\title{
Microcephaly-albinism-digital anomalies syndrome
}

INSERM

\section{Source}

INSERM. (1999). Orphanet: an online rare disease and orphan drug data base.

Microcephaly-albinism-digital anomalies syndrome. ORPHA:2513

Microcephaly - albinism - digital anomalies syndrome is a very rare syndrome associating microcephaly, micrognathia, oculocutaneous albinism, hypoplasia of the distal phalanx of fingers and agenesia of the distal end of the right big toe. 